\title{
LISTENING : A PERSPECTIVE
}

\author{
Dr. Syed Mujahid \\ Faculty of English, \\ V.S. University P.G. Centre, \\ Kavali. A.P.
}

\begin{abstract}
Language is a means of communicating thoughts, feelings, and ideas by human beings. It is a skill that can be learnt by an individual, not simply by knowing but by experiencing it. In the recent years, the shift of focus from the teaching of language as a system to the teaching of language as communication has brought the four language skills viz., listening, speaking, reading, and writing. Among the four skills, Listening is one of the most important skills in learning a language. It is the mother of all skills. It is a verbal skill which requires thoughtful, constructive, purposeful, and critical powers of mind. It is a process of receiving, interpreting and reacting to the messages received from the communication sender. It is an important skill and must be learnt and taught carefully.

The aim of the present paper is to focus on the importance of listening skill in improving communication skills. The paper also discusses various types of listening skills in detail. It also provides some activities through which one may improve ones listening skills.
\end{abstract}

Key words: Language, communication, listening, speaking, hearing, active listening.

Language is a means of communicating thoughts, feelings, and ideas by human beings. It is a skill that can be learnt by an individual, not simply by knowing but by experiencing it. In the recent years, the shift of focus from the teaching of language as a system to the teaching of language as communication has brought the four language skills viz., listening, speaking, reading, and writing.Of these four skills, listening is considered to be a basic skill of learning a language. It is a process of receiving, interpreting and reacting to the messages received from the communication sender. Listening is the mother of all language skills. It is an important skill and must be learnt and taught carefully. Listening is always purposeful.

"God gave us two ears and one mouth, so we ought to listen twice as much as we speak."

Epictetus, who $\rightarrow$ is a Greek Stoic Philosopher. (55-135 A.D).

"First listen, my friend, and then you may shriek and bluster." (Aristophanes).

"Speech is difficult, but Silence is impossible". The Chinese sage who made this profound statement hundreds of years 
ago knew very well the pivotal role of listening in making communication effective.

'Listening' helps to build trust and enables self-disclosure. Jesus frequently finalized his teaching of truth with "Let the one who has ears to hear, hear". In this manner, he suggested that the listener must become involved if a hearing is to truly take place. In the Old Testament, when given opportunity to request anything of God, Solomon asked for a listening heart. He wanted to hear with the inner ear. Though this word is usually translated "understanding or discerning", the Hebrew literally means "hearing". God granted Solomon a wise and listening heart, made competent to hear with the inner ear and discern wisdom in ruling his people. Listening is the most powerful tool of communication. Listening is the first step to comprehension. People listen more than they speak, read or write. Rankin (1929) gives the following statistics about the time spent by adults in different occupations on the four functions of language: Listening $45 \%$, Speaking 30\%, Reading 16\%, and Writing 9\%. A study conducted by Barker, Edwards, Gaines, Gladney, and Holley (1980) confirmed that, students in colleges and schools listen and write more than others as the following figures show: Listening 53\%, Speaking 16\%, Reading $17 \%$, and Writing 14\%. Listening and speaking are interdependent but without effective listening, speaking cannot contribute to meaningful, and mutually supportive, human communication.
During the past two decades, communication and proficiency oriented approaches to language teaching have placed an increasing importance on the development of listening skills. Even the recent experiments have proved that listening is an important skill associated with comprehension of ideas and acceptance or rejection of messages. Jane Willis (1981) points out that,

Listening is receptive rather than productive, but it is an equally important skill. Students need to learn how to listen and to get the chance to listen to different types of English, so they will be able to listen with understanding to spoken English outside the classroom. (134).

In the present context of advanced communication technology, we frequently resort to oral and aural communication for most transactions. We use the telephone, the mobile phone, voice mail, video conferencing, electronic chat and several other means to supplement face-to-face conversation. In these and more, listening determines the usefulness or futility of feedback, according to whether it is good or bad listening.

\section{Listening vs Hearing :}

There is a clear distinction between 'listening' and 'hearing'. How many times 
we have shouted at our children or subordinates saying "Are you listening?" We never use the word 'hearing'. The process of listening is both a physical and a mental act that involves both the ears and the mind. Listening is also a bigger canvas as it consists of receiving information, editing and storing it, trying to build a gestalt, recalling associated information from your experience and then giving feedback. This feedback may consist of a response or may be just the storage of the information. It also includes the ability to grasp fully what someone is saying in words. We pay conscious attention and efforts when we listen. A good listener learns a language more effectively and efficiently. Listening with a purpose results in better comprehension and retention. On the other hand, hearing is simply the act of perceiving sound by the ear. It is just a physical act. If one is not hearingimpaired, hearing simply happens. When we 'hear' we do not pay much attention. We may hear any sound consciously or unconsciously and forget it soon. There is no communication without listening. Hence, listening is said to be a basic skill in the process of learning a language.

\section{Factors affecting the Listening Process :}

There are several factors affect the listening process. These factors may be broadly divided into :

- Factors related to the listener.

- Factors related to the speaker.

- Visual support that accompanies the message.

\section{Factors related to the Listener :}

- Interest in a topic - It increases the listener's comprehension, the listener may tune out topics that are not of interest.

- The content of the topic - The extent of listening increases when the content of the message is familiar, and easy to comprehend. The extent of listening decreases when the content has unfamiliar vocabulary, or for which the listener does not have much background knowledge.

- Negotiation skills - Further, the ability to use negotiation skills, such as asking for clarification, repetition or definition of points hasn't understood enables to the listener to make sense of the information.

\section{Factors related to the Speaker :}

- Language forms - The voice of words, and the form of language used, also have a bearing on the listening process. The extent to which the speaker uses colloquial language, and reduced forms impacts comprehension. The more exposure the listener has to them, the greater will be the ability to comprehend.

- Style - A speaker's pace of delivery, and the frequency and extent of hesitations affect the listening process.

- Speech habits - The speaker can be better understood, if the listener is aware of the corrections, and use of rephrasing ("Well...I mean...That is...") employed by the speaker. The speech habits of the speaker act as clues 
to interpreting what the speaker actually means to say.

\section{Visual Support :}

- Visual support used by the speaker can increase comprehension if the listener is able to correctly interpret it.

- Visual support includes videos, pictures, diagrams, gestures, facial expressions and body language.

\section{Types of Listening :}

Listening may be classified into the following various types on the basis of purpose and output.

- Superficial Listening : In this type of listening the listener has little awareness of the content of what is being said. The output in this type of listening is zero because the listener tends to ignore the message, and is not able to concentrate on the theme, main points, and supporting details of the message.

- Appreciative listening : The main purpose of appreciative listening is to get enjoyment and aesthetic pleasure. Examples include listening to entertaining stories, jokes, anecdotes, listen to a comedian, musician or entertainer and so on.

- Active listening : Active listening is also known as 'intensive listening' or 'attentive listening', with total attention given to the speaker and his message. It is basically attentive and intelligent listening in situations such as group discussions, meeting, job interviews, and so on. The listener pays attention to all parts of the message, that is, the central idea, main points, supporting details, examples, and illustrations. There is no 'selective dismissal' of any part of the oral message.

As an attentive listening is interactive and productive, facilitating proper interaction and more effective listener-speaker relationships, it requires conscious effort on the part of the listener and demands concentration, involvement, and responsibility. Some other examples of attentive listening include listening to administrative instructions, formal conversational interaction, suggestions, requests, important telephone calls, and so on.

- Content Listening : Listening for information about a business activity is essential to make it successful. This type of listening is crucial to the introduction of new products, plans, administrative procedures, welfare schemes, business expansions and many others. Inadequate and wrong understanding may result, if listening is not effective.

- Discriminative Listening : This is essential to the right understanding of an oral report, plea or complaint. The listener should discriminate between truth and error by distinguishing what is said from what is not said, real estate of things from overestimation and a transparent speaker from one who misleads.

- Critical Listening : This is also a form of 'discriminative listening'. It is also known as 'evaluative listening'. This is context-free and applies to one who listens to any speaker. A critical listener 
grasps the main focus of a speech, its essential ideas and purpose. He or she weighs and evaluates what is spoken from the point of view of logic, context, contribution or otherwise, relevance and overall quality. The speaker's intentions, motives and credibility are also analysed. Listening to debriefing, after the execution of a business strategy, presentation of proposals by others for investment, etc., require critical listening.

The main purpose of 'critical listening' or 'evaluative listening' is to evaluate the content of the oral message to select appropriate information. The output could be an oral response, or summarizing and recalling information at a later stage.Examples include listening to structured talks, classroom lectures, workshops, seminars, and so forth.

- Empathic Listening : This has psychological therapeutic value. A relaxed and reassuring atmosphere is necessary to make the speaker feel confident while he or she is tensed. Empathetic listening is listening not only to what the speaker is saying, but also to how he/she is saying, that is, his/her feelings, emotions, and state of mind. The listener has to understand and respond to the affective signals that the speaker might make, and has to be alert to the speaker's implied meaning, intention, and attitude. Moreover, he/she has to understand and interpret non-verbal clues and the body language of the speaker.

\section{The Listening Process :}

Listening like other skills, should be understood as a process. It is ultimately the teacher, who creates opportunities for students to practice listening, by engaging them into activities. The purpose behind such activities is to understand how much students register and how they react to them in the different phases of the listening process. These three phases are - prelistening, while-listening, and postlistening - help the teachers and students to involve themselves in meaningful listening activities.

- Pre-listening, during which the students are set to prepare to listen.

- While listening, during which they are set to focus their attention on the listening text and guide the development of their understanding of it.

- Post-listening, during which the students are set to integrate what they have learnt from the text into their existing knowledge.

a) Pre-listening : There are certain goals that should be achieved before students attempt to listen to any text. These are motivation, contextualization, and preparation.

\section{- Motivation}

It is enormously important that before listening students are motivated to listen, so one should try to select a text that they will find interesting and then design tasks that will arouse the students' interest and curiosity. 
ELK

Asia Pacific Journals

- Contextualization

When one listens in our everyday lives one hears language within its natural environment, and that environment gives us a huge amount of information about the linguistic content one is likely to hear. Listening to a tape recording in a classroom is a very natural process. The text has been taken from its original environment and tasks are to be designed to help students to contextualize the listening and access their existing knowledge and expectations to help them understand the text.

\section{- Preparation}

To do the task students are set while they listen there could be specific vocabulary or expressions that students will need. It's vital that we cover this before they start to listen as we want the challenge within the lesson to be an act of listening not of understanding what they have to do.

b) While listening :

When something is listened in everyday lives, it is done for a reason. Students too need a reason to listen that will focus their attention. For the students to really develop their listening skills they will need to listen a number of times - three or four usually work quite well - as it is found that many students when they listen to a text for the first time they are nervous and have to tune in to the accents and the speed at which the people are speaking.
ELK Asia Pacific Journals - Special Issue

ISBN: 978-81-930411-1-6

Ideally the listening tasks that are designed for them should guide them through the text and should be graded so that the first listening task they do is quite easy and helps them to get a general understanding of the text. Sometimes a single question at this stage will be enough, not putting the students under too much pressure.

The second task for the second time students listen should demand a greater and more detailed understanding of the text. Make sure that the task doesn't demand too much of a response. Writing long responses as they listen can be very demanding and is a separate skill in itself, so keep the tasks to single words, ticking or some sort of graphical response.

The third listening task could just be a matter of checking their own answers from the second task or could lead students towards some more subtle interpretations of the text.

Listening to a foreign language is a very intensive and demanding activity and for this reason it's very important that the students should have 'breathing' or 'thinking' space between listening. The students are asked to compare their answers between listening as this gives them the chance not only to have a break from the listening, but also to check their understanding with a peer and so reconsider before listening again. 
c) Post-listening : There are two common forms that post-listening tasks can take. These are reactions to the content of the text, and analysis of the linguistic features used to express the content.

\section{- Reaction to the text}

Of these two, tasks that focus students' reaction to the content are most important. Again, this is something that has naturally done in our everyday lives. Because we listen for a reason, there is generally a following reaction. This could be discussed as a response to what has been heard - do they agree or disagree or even believe what they have heard? - or it could be some kind of reuse of the information they have heard.

\section{- Analysis of language}

The second of these two postlistening task types involves focusing students on the linguistic features of the text. This is important in terms of developing their knowledge of language, but less so in terms of developing students' listening skills. It could take the form of an analysis of verb forms from a script of the listening text or vocabulary or collocation work. This is a good time to do focused work as the students have already developed an understanding of the text and so will find dealing with the forms that express those meaning much easier.

\section{Obstacles to Effective Listening :} There are certain barriers in listening, to make listening effectively, we need to overcome the obstacles in the way. Few of them are :

- Psychological Ear Muffs : It is a state of split attention, and half listening where full attention and clear understanding are necessary.

- Distraction of Mind : Control and screen out of distractions is very important. The distractions can be external, internal, physical or mental. While listening to a speaker on a particular subject, thinking on some other irrelevant and unwanted matter is a distraction.

- Lack of interest : Showing lack of interest to the speaker's content is another form of barrier to effective listening.

- Conflict of the attitudes and values of the listener with those of the speaker.

- Closed mindedness of the listener.

- Noise : Noise is anything that hangs like a cloud over the entire communication network.

- Status : Listeners' status consciousness, especially when the listener is superior and the speaker is subordinate.

- The mental argument with the speaker before comprehending the total message.

- Wrong perception of the message.

- Listeners' inadequate knowledge of the language used by the speaker. 
- Misunderstanding of correct pronunciation.

- Lack of Vocabulary - difficulty to understand the new terms.

\section{Strategies to Improve the Listening} Skills :

The following are some of the suggestions which will improve the listening skills.

- Be Prepared to Listen - What is most important is the willingness to listen and understand what the speaker is trying to say. You cannot fully hear the speaker's point of view or process information when you argue mentally, or judge what is being said before it is completed. Listen with an open mind. An open mind is a mind that is receiving and listening to information.

- Maintain eye and face contact with the speaker - Look at the speaker. Our eyes can pickup non-verbal signals that all people send out when they are speaking. Moreover, eye contact keeps pupil focused on the task at hand, and keeps them involved in the subject. Our faces contain most of the receptive equipment in our bodies. So it is only natural that we should tilt our faces towards the channel of information.

- Focus on content, not delivery - Pay attention to the content rather than the mannerisms of the speaker. For example, if your are counting the number of times the speaker clears his throat or says a particular word, it means you are not focusing on content.

- Avoid emotional involvement When you are emotionally occupied in listening, you are likely to hear what you want to hear, and not what is actually being said.

To conclude, we may say that listening is an important component of communication. However, for effective listening one has to work consistently and cohesively to learn how to listen effectively and also to interpret and infer the meaning rightly by decoding the message.

\section{References}

[1] Aslam, Mohammad. Teaching of English. New Delhi : Cambridge University Press India Private Limited, 2009. Print.

[2] Barker, L., Edwards, R., Gaines, C., Gladney, K., \& Holley, F. "An investigation of proportional time spent in various communication activities by college students". Journal of Applied Communication Research. 8, 101-110. 1980. Print.

[3] Kaushik, Sharda, \& Bindu Bajwa. A Handbook of Teaching English. New Delhi : Orient Blackswan Private Limited, 2009. Print.

[4] Rankin, P. 'Listening ability'. Proceedings of the Ohio State Educational Conference. Columbus, $\mathrm{OH}$ : Ohio State University Press. 1929. Print. 
ELK

Asia Pacific Journals

[5] Saraswathi, V. English Language

Teaching: Principles and Practice.

Chennai : Orient Longman Private Limited, 2004. Print.

[6] Willis. Jane. Teaching English through English. Harlow, Essex, England :

Longman Group Pvt. Ltd. 1981. Print.
ELK Asia Pacific Journals - Special Issue ISBN: 978-81-930411-1-6 